\title{
High Hydrogen Permeance Silica Membranes Prepared by a Chemical Vapor Deposition Method
}

\author{
Ayumi Ikeda, Ryuhei Ono and Mikihiro Nomura*
}

\author{
Department of Applied Chemistry, Shibaura Institute of Technology, Japan
}

\begin{abstract}
H}_{2}$ permselective silica hybrid membranes were successfully prepared by using a counter diffusion chemical vapor deposition (CVD) method. Hexyltrimethoxysilane (HTMOS), phenyltrimethoxysilane (PhTMOS) or diphenyldimethoxysilane (DPhDMOS) were used as silica precursors. The oxidants were $\mathrm{O}_{3}$ or $\mathrm{O}_{2}$. These reactants were provided at the opposite side of the $\gamma$-alumina substrates, and the deposition occurred in the pores of the substrates. The $\mathrm{HTMOS} / \mathrm{O}_{3}$ derived membrane deposited at $450^{\circ} \mathrm{C}$ showed the highest $\mathrm{H}_{2}$ permselectivity. The $\mathrm{H}_{2}$ permeace was $2.1 \times 10^{-6} \mathrm{~mol} \mathrm{~m}^{-2} \mathrm{~s}^{-1} \mathrm{~Pa}^{-1}$ with the $\mathrm{H}_{2} / \mathrm{SF}_{6}$ permeance ratio of $5.9 \times 10^{6} . \mathrm{H}_{2}$ permeances through the HTMOS derived membranes increased with increasing the deposition temperatures. While the $\mathrm{H}_{2}$ permeance through the PhTMOS and DPhDMOS derived membranes decreased with increasing the deposition temperatures. The PhTMOS derived membrane prepared at $150^{\circ} \mathrm{C}$ showed the $\mathrm{H}_{2}$ permeance of $1.7 \times 10^{-6} \mathrm{~mol} \mathrm{~m}^{-2} \mathrm{~s}^{-1} \mathrm{~Pa}^{-1}$ with the $\mathrm{H}_{2} / \mathrm{SF}_{6}$ permeance ratio of 13. The PhTMOS membrane prepared at $320^{\circ} \mathrm{C}$ showed the highest $\mathrm{H}_{2} / \mathrm{SF}_{6}$ permeance ratio of $1.8 \times 10^{4} \mathrm{among}$ the PhTMOS derived membranes. However, the $\mathrm{H}_{2} / \mathrm{SF}_{6}$ permeance ratio through the DPhDMOS membranes showed the different trend. Higher $\mathrm{H}_{2} / \mathrm{SF}_{6}$ permeance ratio was found through the DPhDMOS derived membranes deposited at $180^{\circ} \mathrm{C}$ and $360^{\circ} \mathrm{C}$. The maximum $\mathrm{H}_{2} / \mathrm{SF}_{6}$ permeance ratio was $4.2 \times 10^{4}$ through the DPhDMOS membrane deposited at $180^{\circ} \mathrm{C}$. The decomposition properties of organic groups on silica surface are investigated by using hydrolysis powders derived from the each silica precursor. The HTMOS powders showed $\mathrm{O}_{3}$ stability after the high temperature treatment. Thus, high $\mathrm{H}_{2}$ permselective membranes were prepared by the HTMOS at $450{ }^{\circ} \mathrm{C}$.
\end{abstract}

Keywords: Silica hybrid membrane, counter diffusion CVD method, $\mathrm{H}_{2}$ permselective membrane, pore size control, silica precursors.

\section{Introduction}

Recently, hydrogen is expected as a clean energy and as an energy carrier. Hydrogen takes gas state under ordinary pressure and temperature. To use liquefied hydrogenas transportation compounds, it is necessary to cool hydrogen until cryogenic temperature. The hydrogen transport materials are required safety, low cost and saving energy. Therefore, organic hydrides such as methylcyclohexane are concerned as can-didates to transport hydrogen. Separation to remove hydrogen from the organic hydrides should be operated efficiently. We have focused on a separation technique by using hydrogen permselective membranes for efficient hydrogen separation. The hydrogen permselective membranes require thermal stability due to the hydrogen decomposition temperature from the organic hydrides. Thus, many researches for hydrogen permselective ceramic membranes have been reported for the silica membranes.

The silica membranes have been prepared by using a sol-gel method [1-3] or a chemical vapor deposition (CVD) method [4-14]. In this paper, we discussed about the silica membranes prepared by using a CVD

*Address correspondence to this author at the Separation Systems Engineering Laboratory, Department of Applied Chemistry, Shibaura Institute of Technology, T135-8548, 12G-27, 3-7-5, Toyosu, Koto-ku, Tokyo, Japan; Tel: 03-5859-8160; Fax: 03-5859-8160; E-mail: Lscathy@shibaura-it.ac.jp method. There were several kinds of the silica precursors used in the former reports such as silane $\left(\mathrm{SiH}_{4}\right)$ [4], silicon tetrachloride $\left(\mathrm{SiCl}_{4}\right)$ [6], tetratrimethoxysilane (TMOS) $[9,13]$ and tetratriethoxysilane (TEOS) [7-8]. The geometries of the CVD methods are important. The CVD methods are classified in two kinds by the direction to supply the reactants. All the reactants are provided from the one side of a porous substrate for the one-side CVD method, and two reactants are provided at the opposite side of the porous substrates for the counter diffusion CVD method. The $\mathrm{H}_{2} / \mathrm{N}_{2}$ permeance ratio of 880 through the membrane prepared by the one-side CVD method [7]. Nakao et al. [8] reported that the silica membrane was prepared by the counter diffusion CVD of TEOS/ $\mathrm{O}_{3}$ at $150-200^{\circ} \mathrm{C}$. This membrane was obtained the $\mathrm{He}$ permeance of $3 \times 10^{-8} \mathrm{~mol} \mathrm{~m}^{-2} \mathrm{~s}^{-1} \mathrm{~Pa}^{-1}$ with the $\mathrm{He} / \mathrm{N}_{2}$ permeance ratio of 950. Gapalakrishman et al. [11] reported that the $\mathrm{H}_{2}$ permeance of $6.4 \times 10^{-7} \mathrm{~mol} \mathrm{~m}^{-2} \mathrm{~s}^{-1}$ $\mathrm{Pa}^{-1}$ with a $\mathrm{H}_{2} / \mathrm{N}_{2}$ permeance ratio of 2,343 at $600^{\circ} \mathrm{C}$ through the membrane prepared by the counter diffusion CVD method of the $\mathrm{TMOS} / \mathrm{O}_{2}$ systems. They also obtained the three membranes module by usingthe counter diffusion CVD method [13]. Such a complex shape modules can be prepared by the CVD method that indicates apractical application of a membrane reactor.

Nomura et al. [14] used propyltrimethoxysilane (PrTMOS) as a silica precursor for the counter diffusion 
CVD method. The $\mathrm{H}_{2}$ permeance of $1.3 \times 10^{-7} \mathrm{~mol} \mathrm{~m}^{-2} \mathrm{~s}^{-1}$ $\mathrm{Pa}^{-1}$ was obtained with an $\mathrm{H}_{2} / \mathrm{N}_{2}$ permeance ratio of 30 . The pore size of the silica hybrid membranes can be controlled by changing the deposition conditions due to the part of decomposition of the propyl groups in the silica precursor. HTMOS derived membranes have been developed for the propylene/propane separation [15]. The propylene/propane permeance ratio at $270^{\circ} \mathrm{C}$ was 414 (propylene permeance $1.0 \times 10^{-8} \mathrm{~mol} \mathrm{~m}^{-2} \mathrm{~s}^{-1}$ $\mathrm{Pa}^{-1}$ ) through the $\mathrm{HTMOS} / \mathrm{O}_{2}$ membrane deposited at $450^{\circ} \mathrm{C}$. Ikeda et al. [16] reported silica reverse osmosis membrane prepared by PhTMOS as a silica precursor. However, the decomposition conditions for hydrogen permselective membrane were not clear. The organic groups of silica precursor can be changed such as hexyl group or phenyl group.

In this study, hydrogen permeabilities through three kinds of silica hybrid membranes by using the counter diffusion CVD method were discussed. The decomposition properties of organic groups on the silica surface were investigated by thermogravimetry (TG), the FT-IR measurements and temperature programmed desorption (TPD) with a mass spectrometry (MS). In order to develop the hydrogen permselective silica membranes for the dehydration of organic hydride, we have evaluated the $\mathrm{H}_{2} / \mathrm{SF}_{6}$ permeance ratio. The kinetic diameter of $\mathrm{SF}_{6}$ is 0.55 $\mathrm{nm}$ that is similar to that of methylcyclohexane.

\section{EXPERIMENTAL}

\subsection{Preparation of Membranes}

Figure 1 shows the schematic diagram of an apparatus for a counter diffusion CVD method. Porous $\mathrm{Y}$-alumina substrates (effective length: $40 \mathrm{~mm}$, pore size: $4 \mathrm{~nm}$ ) were provided by NOK Co. CVD was carried out at between $150-500^{\circ} \mathrm{C}$ for $5-90 \mathrm{~min}$. Hexyltrimethoxysilane (HTMOS), phenyltrimethoxysilane (PhTMOS) or diphenyldimethoxysilane (DPhDMOS) was employed as a silica source (ShinEtsu Chem. Co.). Figure 2 shows the structures of the silica precursors. HTMOS, PhTMOS or DPhDMOS were provided through the $\mathrm{N}_{2}$ bubbler kept at 75$125^{\circ} \mathrm{C}$ and the vapor was introduced to the outside of the alumina substrate. $\mathrm{O}_{3}$ was produced by using an $\mathrm{O}_{3}$ generator (SOW-5000R, SYOKEN Co.). $\mathrm{O}_{3}$ from the $\mathrm{O}_{3}$ generator was introduced into the membrane module at $0.2 \mathrm{~L} \mathrm{~min}^{-1}$. The CVD conditions of each silica precursors are shown in Table 1.

\subsection{Gas Permeation Test}

Single gas permeances of $\mathrm{H}_{2}$ (kinetic diameter: 0.29 $\mathrm{nm}), \mathrm{N}_{2}(0.36 \mathrm{~nm}), \mathrm{C}_{3} \mathrm{H}_{6}(0.45 \mathrm{~nm}), \mathrm{C}_{3} \mathrm{H}_{8}(0.43 \mathrm{~nm})$ and $\mathrm{SF}_{6}(0.55 \mathrm{~nm})$ were performed at the deposited temperatures of the membranes below the $270^{\circ} \mathrm{C}$ deposition. If the membranes were deposited over $270^{\circ} \mathrm{C}$, permeances were measured at $270^{\circ} \mathrm{C}$. The permeance was measured through a pressure-change

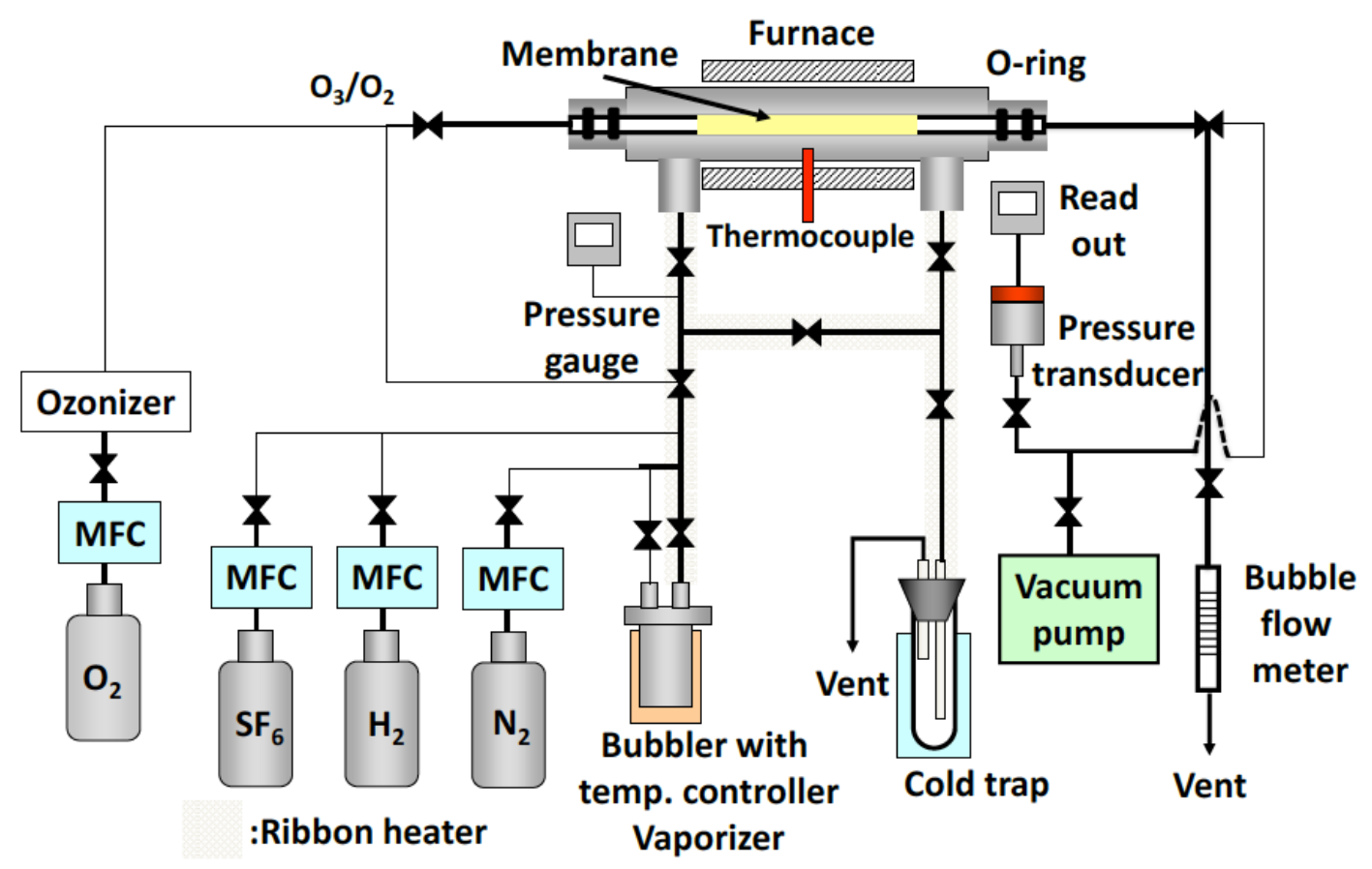

Figure 1: Schematic diagram of the CVD/permeation apparatus. 
HTMOS

Hexyltrimethoxysilane

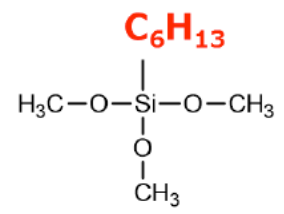

PhTMOS

Phenyltrimethoxysilane

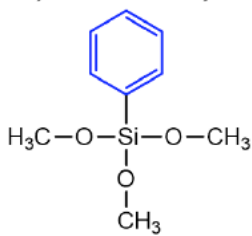

DPhDMOS

Diphenyldimethoxysilane

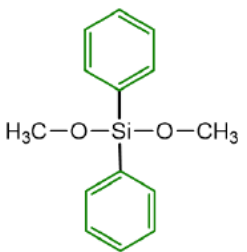

Figure 2: Chemical formulas of silica precursors.

Table 1: The CVD Conditions of Each Silica Precursors

\begin{tabular}{|c|c|c|c|}
\hline Silica precursor & Bubbler temp. $\left({ }^{\circ} \mathrm{C}\right)$ & O $_{3}$ flow rate $\left(\mathrm{L} \mathrm{min}^{-1}\right)$ & CVD time (min) \\
\hline \hline HTMOS & 125 & 0.2 & 5 \\
\hline PhTMOS & 75 & 0.2 & 90 \\
\hline DPhDMOS & 125 & 0.2 & 90 \\
\hline
\end{tabular}

method. Three gases were provided independently to the outside of the membrane. The inner side of the membrane was evacuated, and the rate of the pressure change at the inside of the membrane was measured by turning off the valve between the module and the vacuum pump.

\subsection{The Thermal Decomposition Properties of the Silica Hydrolysis Powders}

Powder samples were prepared in order to discuss the decomposition of the organic groups on the silica surface. HTMOS, PhTMOS or DPhDMOS was stirred at $80^{\circ} \mathrm{C}$ for $2 \mathrm{~h}$ in ethanol (Wako Pure Chem. Ind.). The molar compositions of the sol were HTMOS: EtOH: $\mathrm{H}_{2} \mathrm{O}: \mathrm{NaOH}=1$ : 3.8: 42: 2.5, PhTMOS: $\mathrm{EtOH}: \mathrm{H}_{2} \mathrm{O}$ : $\mathrm{NaOH}=1: 3.8: 30: 1.3$ and DPhDMOS: $\mathrm{EtOH}: \mathrm{H}_{2} \mathrm{O}$ : $\mathrm{NaOH}=1: 3.8: 30: 1.3$ respectively. After the stirring, the obtained gel was dried at $100^{\circ} \mathrm{C}$ for $12 \mathrm{~h}$. The dried powder samples were set in the center of the quartz tube $(\varphi: 2 \mathrm{~mm})$ and $\mathrm{O}_{3}$ in $\mathrm{O}_{2}$ was provided at $0.2 \mathrm{~L}$ $\min ^{-1}\left(49.7 \mathrm{~g} \mathrm{~m}^{-3}\right)$. The treatments were conducted at $150-450^{\circ} \mathrm{C}$ for $90 \mathrm{~min}$. The treated powder samples were evaluated by using TG (TGA 50, Shimadzu Co.) and FT-IR (FTIR-8400S, Shimadzu Co.). Thermal decomposition of phenyl groups (mass-tocharge: $\mathrm{m} / \mathrm{z}=78$ ) on the PhTMOS and the DPhDMOS derived powders were measured by the TPD (BELCAT, MicrotracBEL) with the MS (BELMass, MicrotracBEL).

\section{RESULTS AND DISCUSSIONS}

In the preparation of the silica hybrid membranes contained organic groups by using a counter diffusion
CVD method, the decomposition properties of organic groups on the silica surfaces were the important factor as controlling the pore size of the deposited membranes. Firstly, the HTMOS, the PhTMOS and the DPhDMOS derived powders were measured by $T G$ in $\mathrm{N}_{2}$ atmosphere. Figure 3 shows the TG curves of the hydrolysis powders. A weight loss of the HTMOS derived powder decreased sharply from $330^{\circ} \mathrm{C}$ to $450^{\circ} \mathrm{C}$. The decomposition temperatures of the PhTMOS and the DPhDMOS derived powders were $50^{\circ} \mathrm{C}$ lower than that for the HTMOS derived powders. The hexyl groups on silica surface has higher thermal stability than the organic groups derived from PhTMOS and DPhDMOS. It indicates that this difference of the thermal stability must be related to the thermal decomposition of the organic groups during the CVD procedures. Thus, the deposition temperature for the CVD should be investigated. The decomposition temperature ranges of the PhTMOS and the DPhDMOS derived powders were from $280^{\circ} \mathrm{C}$ to $380^{\circ} \mathrm{C}$, while a weight loss of the DPhDMOS derived powder was about $15 \%$ lower than that of the PhTMOS derived powder. It can be explained by the numbers of the phenyl groups in the silica precursors. Next, the difference of the number of phenyl groups in the silica precursors were studied by using the TPD with a MS. Figure 4 shows the intensity of $\mathrm{m} / \mathrm{z}=78$ by changing the temperature from $100^{\circ} \mathrm{C}$ to $500^{\circ} \mathrm{C}$. This intensity shows the amounts thermally decomposed phenyl groups. In comparison with Figure 3, it seems that the difference between PhTMOS and DPhDMOS is larger. However, it is not the case because this vertical axis was log scale. From the result shown in this figure, the 
decomposition of phenyl groups can be classified in two steps at $300^{\circ} \mathrm{C}$. The intensity of the DPhDMOS derived powder were changed ten times the PhTMOS derived powders higher than $300^{\circ} \mathrm{C}$. It indicates that thermal stability over $300^{\circ} \mathrm{C}$ for the DPhDMOS membrane might be lower than that for the PhTMOS membrane. PhTMOS has three methoxy groups ($\left.\mathrm{OCH}_{3}\right)$ in one molecule, while DPhDMOS has two methoxy groups (cf. Figure 2). The silica network derived from PhTMOS must be a three-dimensional mesh shape, while that derived from DPhDMOS should

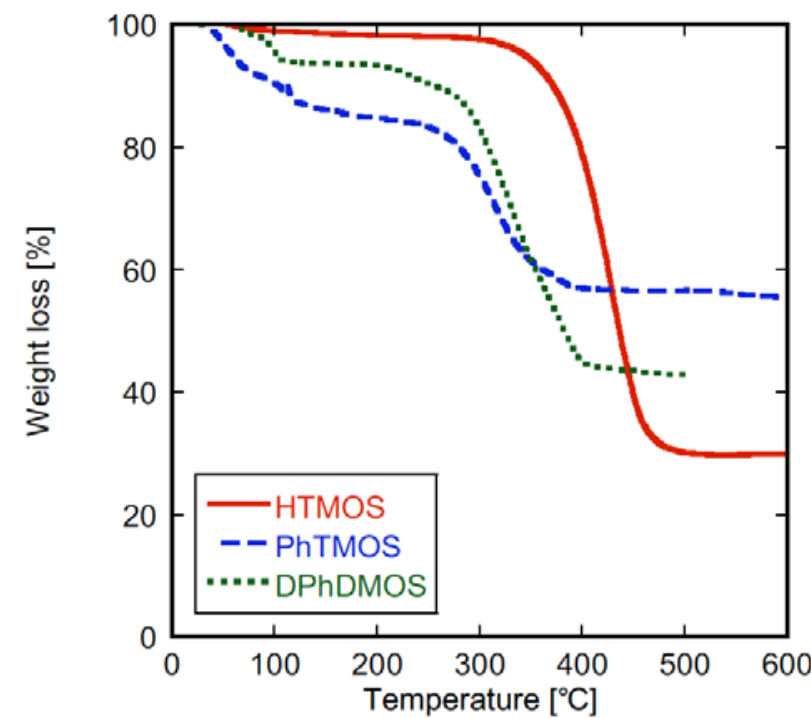

Figure 3: Thermogravimetric curves of hydrolysis powders of silica precursors (Heating rate: $5^{\circ} \mathrm{C} \mathrm{min}^{-1}, \mathrm{~N}_{2}$ flow rate: $50 \mathrm{~mL}$ $\min ^{-1}$ ).

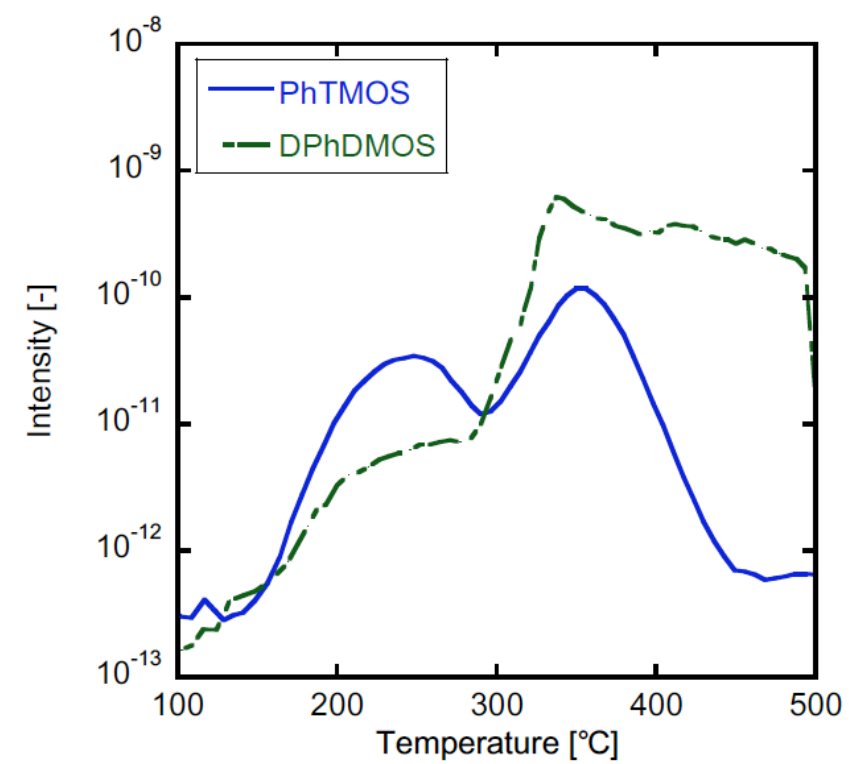

Figure 4: Temperature programmed desorption of the PhTMOS and the DPhDMOS derived hydrolysis powders (Heating rate: $5^{\circ} \mathrm{C} \mathrm{min}^{-1}$, He flow rate: $30 \mathrm{~mL} \mathrm{~min}^{-1}, \mathrm{~m} / \mathrm{z}=78$ ). be linear structures. The thermal stability difference between PhTMOS and DPhDMOS can be explained by the silica structures based on the numbers of the methoxy groups in the silica precursor.

Next, the decomposition properties of the organic groups in high temperature $\mathrm{O}_{3}$ atmosphere were investigated by using the FT-IR. Figure 5 shows the FT-IR results of the HTMOS, the PhTMOS and the DPhDMOS derived powders after $90 \mathrm{~min}$ of the $\mathrm{O}_{3}$ treatments. The vertical axis shows the absorption ratio at $2,960 \mathrm{~cm}^{-1}\left(\mathrm{C}_{-} \mathrm{CH}_{3}\right)$ or $1,431 \mathrm{~cm}^{-1}\left(\mathrm{Si}-\mathrm{C}_{6} \mathrm{H}_{5}\right)$ of the $\mathrm{O}_{3}$-treated powders over those of the as-made powders. HTMOS was evaluated by the absorption ratio at $2,960 \mathrm{~cm}^{-1}$. PhTMOS and DPhDMOS was evaluated by the absorption at $1,431 \mathrm{~cm}^{-1}$. The absorption ratio of 1 shows all organic groups were remained in the silica hydrolysis powder, while the absorption ratio of 0 shows that no organic group remained on the silica hydrolysis powder by the $\mathrm{O}_{3}$ treatment. The ratio at $2,930 \mathrm{~cm}^{-1}$ decreased from 0.23 to 0.06 with increasing the $\mathrm{O}_{3}$ treatment temperatures for the HTMOS derived powders. This decrease is due to the thermal decomposition. Hexyl groups were remained after the $450^{\circ} \mathrm{C}$ treatment, indicating the high thermal stability for the HTMOS deposition. A maximum ratio of $1,431 \mathrm{~cm}^{-1}$ was 0.54 after $\mathrm{O}_{3}$ treatment at $180^{\circ} \mathrm{C}$ for the PhTMOS derived powder. The $\mathrm{O}_{3}$ concentrations of the outlet of the reactor were measured by the $\mathrm{O}_{3}$ concentration meter [14]. At $300^{\circ} \mathrm{C}$

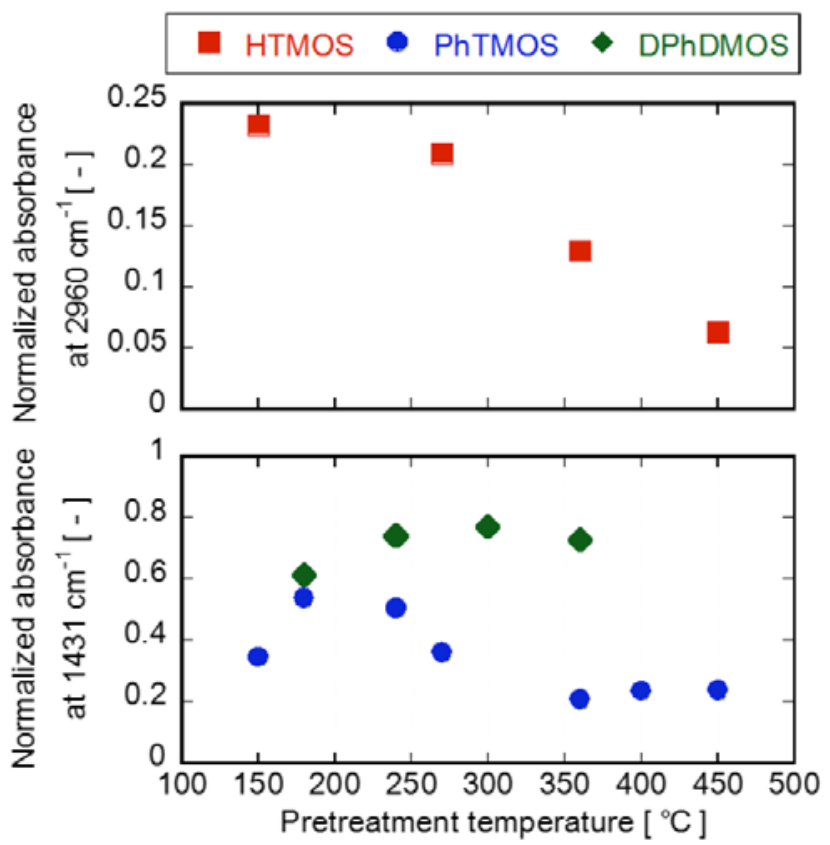

Figure 5: FT-IR measurements for the HTMOS, the PhTMOS or the DPhDMOS derived hydrolysis powders (Pretreatment: $\mathrm{O}_{3}$ flow rate $0.2 \mathrm{~L} \mathrm{~min}^{-1}, 90 \mathrm{~min}$ ). 

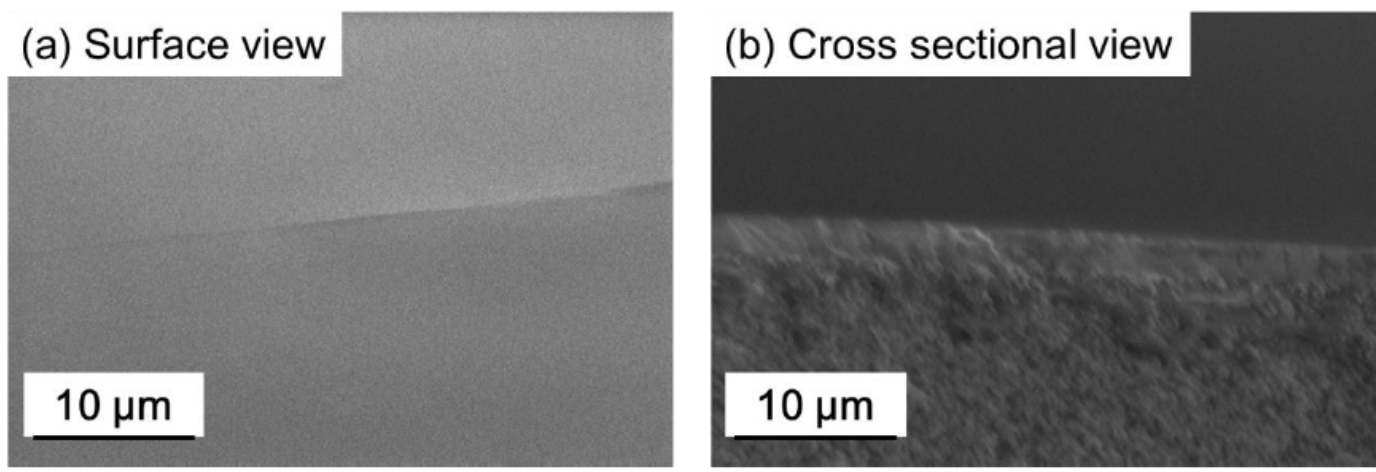

Figure 6: SEM images of the PhTMOS membrane deposited at $300^{\circ} \mathrm{C}$ (a) surface view, (b) cross sectional view.

of the reactor, the $\mathrm{O}_{3}$ concentration was less than half of the feed $\mathrm{O}_{3}$ concentration. Moreover, the $\mathrm{O}_{3}$ concentrations were approximately $0 \mathrm{~g} \mathrm{~m}^{-3}$ at the $400^{\circ} \mathrm{C}$ of the reactor. Therefore, the decomposition of organic groups were due to $\mathrm{O}_{3}$ at less than $300^{\circ} \mathrm{C}$ of the reactor, and $\mathrm{O}_{3}$ must be thermally decomposed at higher than $300^{\circ} \mathrm{C}$ of the reactor. Phenyl groups on the surface of the PhTMOS derived powders remained by the $\mathrm{O}_{3}$ treatments between $150^{\circ} \mathrm{C}$ and $270^{\circ} \mathrm{C}$. This temperature range should be investigated by the CVD. The DPhDMOS derived powders show almost the constant ratio by all the $\mathrm{O}_{3}$ treatment temperatures. These results indicate that the $\mathrm{O}_{3}$ decomposition mechanism for phenyl groups are different from thermally decomposition shown the Figure 4. However, the phenyl groups for the DPhDMOS derived powders were remained below $250^{\circ} \mathrm{C}$, and the deposition conditions for the DPhDMOS derived membrane should be studied at the low deposition temperatures.

Figure 6 shows the SEM images of the PhTMOS derived membrane deposited at $300^{\circ} \mathrm{C}$. The surface image of the membrane shows that the surface of the membrane is smooth with no deposited particles. The SEM image of the cross section shows the PhTMOS derived membrane had two layers. The bottom layer was a-alumina substrate. A porous alumina layer was thickness of $3.5 \mu \mathrm{m}$ on the $\alpha$-alumina substrate. The color of the top of the $\mathrm{y}$-alumina layer was slightly different. This part is thought the silica layer and shows the CVD layer was formed inside the pore of $\mathrm{y}$-alumina substrate. The layer thickness was almost constant regardless of different silica precursors and deposition temperatures. The silica layer thickness was difficult to evaluate because the border of layer was not clear.

Next, the deposition temperature dependency of the gas permeation performance through the HTMOS derived membranes was investigated. Figure 7 shows the $\mathrm{H}_{2}$ permeances and the $\mathrm{H}_{2} / \mathrm{SF}_{6}$ permeance ratios through the HTMOS derived membranes by changing the deposition temperatures. The HTMOS derived membrane deposited at $450^{\circ} \mathrm{C}$ showed the highest $\mathrm{H}_{2}$ permeance of $2.1 \times 10^{-6} \mathrm{~mol} \mathrm{~m}^{-2} \mathrm{~s}^{-1} \mathrm{~Pa}^{-1}$ with the highest $\mathrm{H}_{2} / \mathrm{SF}_{6}$ permeance ratio of $5.6 \times 10^{6}$. The permeance of various gases measured at $270^{\circ} \mathrm{C}$ is shown in Table 2. The $\mathrm{C}_{3} \mathrm{H}_{6} / \mathrm{C}_{3} \mathrm{H}_{8}$ permeance ratio was 353 . Then, the pore size were estimated around $0.45 \mathrm{~nm}$ based on the molecular size of $\mathrm{C}_{3} \mathrm{H}_{6}$ and $\mathrm{C}_{3} \mathrm{H}_{8}$. The $\mathrm{H}_{2} / \mathrm{SF}_{6}$ permeances of more than ten thousand were obtained deposited at the temperature between $400^{\circ} \mathrm{C}$ to $500^{\circ} \mathrm{C}$. This was the same trend to the TG result. The FT-IR measurements of the HTMOS derived powders showed the stability for the high temperature $\mathrm{O}_{3}$ treatments. Slightly remained hexyl groups must be the keys for the high $\mathrm{H}_{2} / \mathrm{SF}_{6}$ selectivity at the $450^{\circ} \mathrm{C}$ deposition of the HTMOS derived membrane.
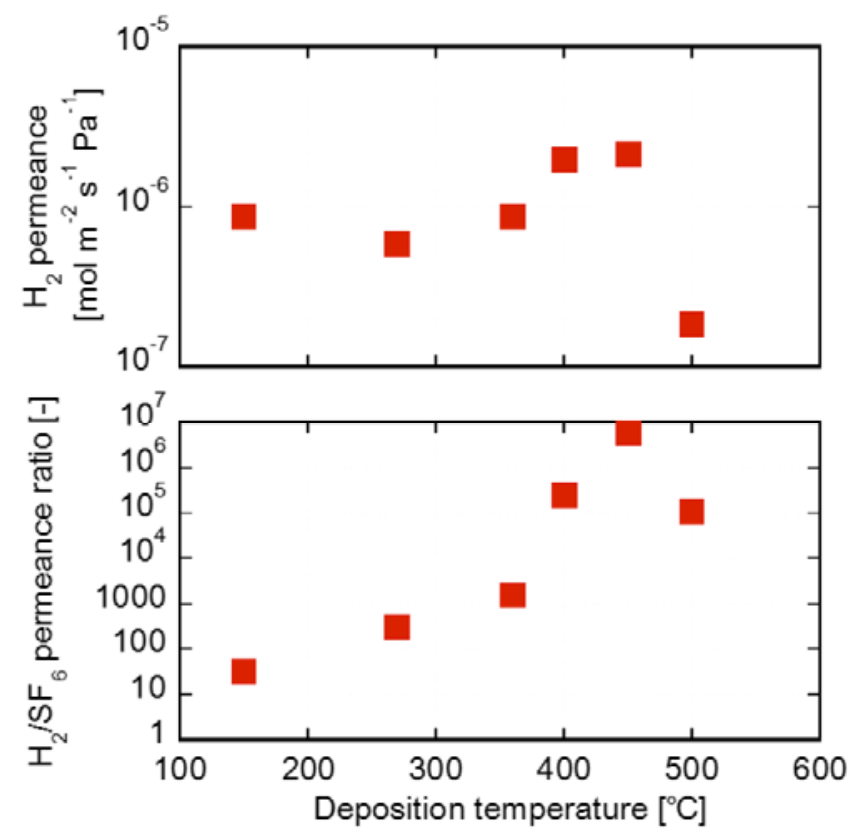

Figure 7: The $\mathrm{H}_{2}$ permeances and the $\mathrm{H}_{2} / \mathrm{SF}_{6}$ permeance ratios through the HTMOS membranes deposited by changing the deposition temperatures. 
Table 2: Single Gas Permeances at $270^{\circ} \mathrm{C}$ through the HTMOS Membrane Deposited at $450^{\circ} \mathrm{C}$

\begin{tabular}{|c|c|c|c|c|c|c|}
\hline \multirow{2}{*}{ Membrane } & \multicolumn{5}{|c|}{ Single permeance $\left(\mathrm{mol} \mathrm{m}^{-2} \mathbf{s}^{-1} \mathbf{P a}^{-1}\right)$} & \multirow{2}{*}{$\mathbf{H}_{2} / \mathbf{S F}_{6}$ permeance ratio [-] } \\
\cline { 2 - 6 } & $\mathbf{H}_{2}$ & $\mathbf{N}_{2}$ & $\mathbf{C}_{3} \mathrm{H}_{6}$ & $\mathbf{C}_{3} \mathrm{H}_{8}$ & $\mathbf{S F}_{6}$ & \\
\hline \hline HTMOS $450^{\circ} \mathrm{C}$ & $2.1 \times 10^{-6}$ & $7.9 \times 10^{-8}$ & $1.2 \times 10^{-9}$ & $3.4 \times 10^{-12}$ & $3.6 \times 10^{-13}$ & $5.9 \times 10^{6}$ \\
\hline
\end{tabular}

Then, the effects of the deposition temperatures were investigated for the PhTMOS and the DPhDMOS derived membranes. Figure $\mathbf{8}$ shows the $\mathrm{H}_{2}$ permeances depending on the deposition temperature through the PhTMOS and the DPhDMOS derived membranes. The PhTMOS derived membrane deposited at $180^{\circ} \mathrm{C}$ showed the highest $\mathrm{H}_{2}$ permeance of $1.7 \times 10^{-6} \mathrm{~mol} \mathrm{~m}^{-2} \mathrm{~s}^{-1} \mathrm{~Pa}^{-1}$ among the PhTMOS derived membranes. While the DPhDMOS derived membrane deposited at $240^{\circ} \mathrm{C}$ showed the highest $\mathrm{H}_{2}$ permeance of $1.3 \times 10^{-6} \mathrm{~mol} \mathrm{~m}^{-2} \mathrm{~s}^{-1} \mathrm{~Pa}^{-1}$ among the DPhDMOS derived membranes. Figure 9 shows the dependence of the $\mathrm{H}_{2} / \mathrm{SF}_{6}$ permeance ratios through the same PhTMOS and the same DPhDMOS derived membranes shown in Figure 8. The PhTMOS derived membrane deposited at $320^{\circ} \mathrm{C}$ showed the highest $\mathrm{H}_{2} / \mathrm{SF}_{6}$ permeance ratio of $1.9 \times 10^{4}$, while the DPhDMOS derived membrane deposited at $180^{\circ} \mathrm{C}$ exhibited the highest $\mathrm{H}_{2} / \mathrm{SF}_{6}$ permeance ratio of $4.2 \times 10^{4}$.

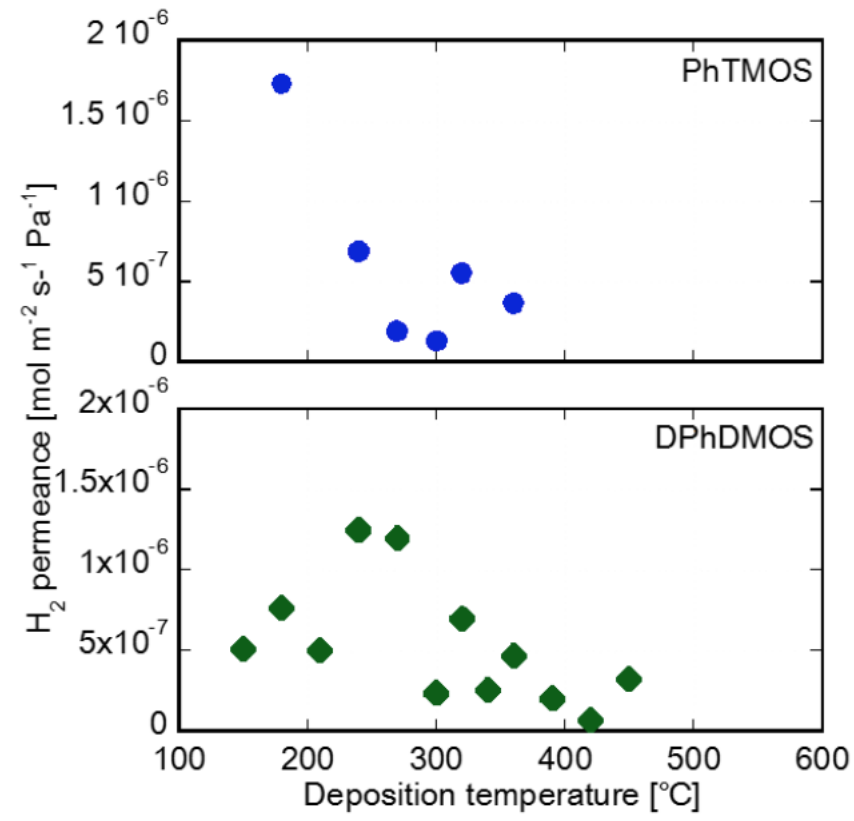

Figure 8: The $\mathrm{H}_{2}$ permeances through the PhTMOS and the DPhDMOS membranes deposited by changing the deposition temperatures.

The performances of the membranes are compared those of the other groups. According to the former report of the silica membrane prepared by the one-side diffusion CVD method, the $\mathrm{H}_{2} / \mathrm{SF}_{6}$ selectivity was above 6,800 with the $\mathrm{H}_{2}$ permeance of around $10^{-6} \mathrm{~mol}$ $\mathrm{m}^{-2} \mathrm{~s}^{-1} \mathrm{~Pa}^{-1}$ at $300^{\circ} \mathrm{C}$ [17]. The hydrogen permeance was $1.0 \times 10^{-6} \mathrm{~mol} \mathrm{~m}^{-2} \mathrm{~s}^{-1} \mathrm{~Pa}^{-1}$ and the selectivity of $\mathrm{H}_{2} / \mathrm{SF}_{6}$ was 10,000 through the organosilica membrane by a sol-gel method [18]. These membranes showed higher $\mathrm{H}_{2}$ permeances at approximately $1.0 \times 10^{-6} \mathrm{~mol}$ $\mathrm{m}^{-2} \mathrm{~s}^{-1} \mathrm{~Pa}^{-1}$. Thus, the HTMOS derived membrane deposited at $450^{\circ} \mathrm{C}$ was obtained the maximum $\mathrm{H}_{2} / \mathrm{SF}_{6}$ permeance ratio. To investigate an effect of number of phenyl group, the PhTMOS and the DPhDMOS derived membranes of the three deposition temperature of $180^{\circ} \mathrm{C}, 300^{\circ} \mathrm{C}$ and $360^{\circ} \mathrm{C}$ were studied. Firstly, the membranes deposited at $180^{\circ} \mathrm{C}$ were discussed. The $\mathrm{H}_{2} / \mathrm{SF}_{6}$ permeance ratios were significantly different between the PhTMOS and the DPhDMOS derived membranes. The $\mathrm{H}_{2} / \mathrm{SF}_{6}$ permeance ratio through the DPhDMOS derived membrane was 3,000 times larger than that through the PhTMOS derived membrane. However, the $\mathrm{H}_{2}$ permeances were the similar through those membranes. The intensity of mass number of 78

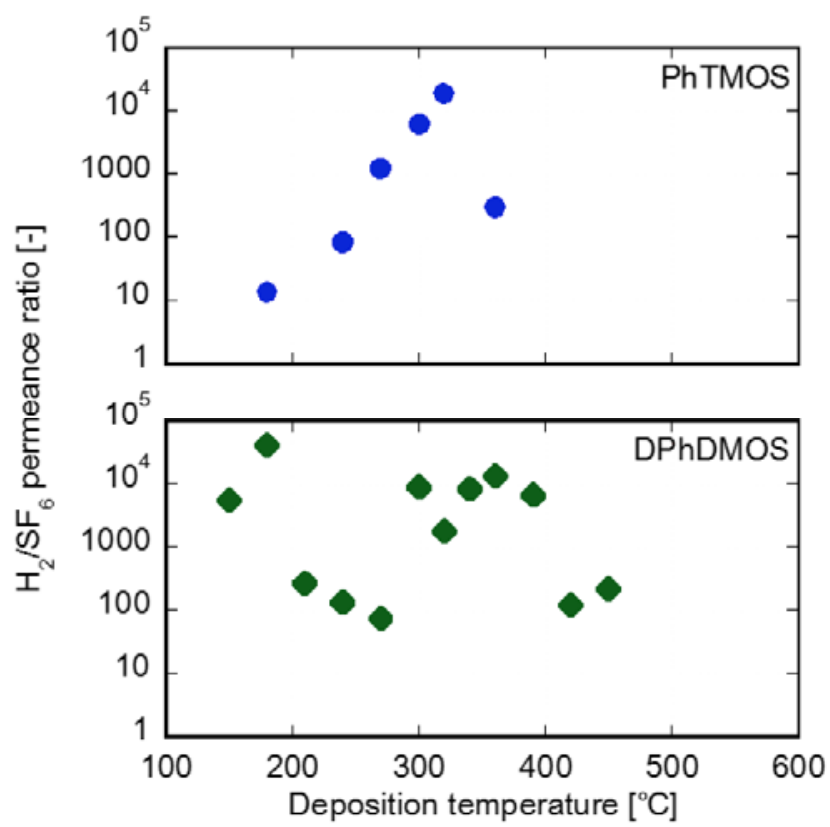

Figure 9: The $\mathrm{H}_{2} / \mathrm{SF}_{6}$ permeance ratios through the PhTMOS and the DPhDMOS membranes by changing the deposition temperatures. 
at $180^{\circ} \mathrm{C}$ for the DPhDMOS derived powder was $1 \times 10^{-12}$ that was the similar to that for the PhTMOS derived powder (Figure 4). This shows that the influence of the precursor difference at $180^{\circ} \mathrm{C}$ decomposition is negligible because of the TPD performed under the $\mathrm{He}$ atmosphere. From the FT-IR measurement (Figure 5 ), the absorption ratio of PhTMOS and DPhDMOS after $\mathrm{O}_{3}$ treatment was 0.53 and 0.61 . Therefore, the decomposition of phenyl groups was greatly affected by $\mathrm{O}_{3}$ at $180^{\circ} \mathrm{C}$. The amounts of phenyl groups for the as-made PhTMOS derived powders are half fartheras-made DPhDMOS derived powder. Thus, the remaining phenyl groups on the silica surface after the $\mathrm{O}_{3}$ treatments for the PhTMOS derived powders were approximately half for the DPhDMOS derived powders. $\mathrm{H}_{2}, \mathrm{~N}_{2}$ and $\mathrm{SF}_{6}$ gas passes easily through the pore formed by the decomposition of phenyl groups because the size of phenyl group is about $0.6 \mathrm{~nm}$ that is larger than $\mathrm{SF}_{6}$ $(0.55 \mathrm{~nm})$. Therefore, the PhTMOS derived membrane deposited at $180^{\circ} \mathrm{C}$ showed the high $\mathrm{H}_{2}$ permeance of $1.8 \times 10^{-6} \mathrm{~mol} \mathrm{~m}^{-2} \mathrm{~s}^{-1} \mathrm{~Pa}^{-1}$ with the low $\mathrm{H}_{2} / \mathrm{SF}_{6}$ permselective membrane of 30 . While the DPhDMOS derived membrane deposited at $180^{\circ} \mathrm{C}$ contained many phenyl groups and the small hole formed among phenyl groups must be smaller than $\mathrm{SF}_{6}$. Therefore the maximum $\mathrm{H}_{2} / \mathrm{SF}_{6}$ permeance ratio of $4.2 \times 10^{4}$ was found to phenyl groups. Amounts of organic groups in the deposited silica layer in the $\mathrm{O}_{3}$ atmosphere was important for the deposition at $180^{\circ} \mathrm{C}$. Secondly, the deposition temperature of $300^{\circ} \mathrm{C}$ was discussed. This temperature was the key point from the TG and the TPD result. Phenyl groups of the PhTMOS and the $\mathrm{DPhDMOS}$ derived powders was remaining at $300^{\circ} \mathrm{C}$. The $\mathrm{H}_{2}$ permeances were $1-1.2 \times 10^{-6} \mathrm{~mol} \mathrm{~m}^{-2} \mathrm{~s}^{-1} \mathrm{~Pa}^{-1}$ with the $\mathrm{H}_{2} / \mathrm{SF}_{6}$ permeance ratios of $8-9 \times 10^{3}$. Finally, the PhTMOS and the DPhDMOS derived membrane deposited at $360^{\circ} \mathrm{C}$ were investigated. According to the result of TPD, DPhDMOS was easy to decompose at the high temperatures over $300^{\circ} \mathrm{C}$. The silica network of the DPhDMOS derived is considered to be the linear structure as described in the former section. The linear structures are flexible not to be thermally stable. Then, it might be created the pinholes which $\mathrm{SF}_{6}$ can pass through. The DPhDMOS derived membrane deposited at $360^{\circ} \mathrm{C}$ showed the $\mathrm{H}_{2}$ permeance of $4.5 \times 10^{-7} \mathrm{~mol} \mathrm{~m}^{-2}$ $\mathrm{s}^{-1} \mathrm{~Pa}^{-1}$ with the high $\mathrm{H}_{2} / \mathrm{SF}_{6}$ permeance ratio of $1.3 \times 10^{4}$. The amount of phenyl groups of the DPhDMOS derived powders at $360^{\circ} \mathrm{C}$ was higher than that of the PhTMOS powders (cf. Figure 3). Hence, the $\mathrm{H}_{2} / \mathrm{SF}_{6}$ selectivity was due to the effects of the remained phenyl groups. However, the PhTMOS derived membranes should be the mesh shape. The silica network of the PhTMOS derived membranes was stable at $360^{\circ} \mathrm{C}$ and the $\mathrm{H}_{2} / \mathrm{SF}_{6}$ permeance ratio of 302. The low $\mathrm{H}_{2} / \mathrm{SF}_{6}$ selectivity was due to the low amounts of the remained phenyl groups. Thus, the thermal stability of phenyl group is affected by the structures of the deposited silica networks at the high deposition temperatures. Figure $\mathbf{1 0}$ shows the $\mathrm{H}_{2}$ permeances through the HTMOS, the PhTMOS and the DPhDMOS derived membranes withthe $\mathrm{H}_{2} / \mathrm{SF}_{6}$ permeance ratios $>1000$. These membranes have the excellent $\mathrm{H}_{2} / \mathrm{SF}_{6}$ selectivity. The big difference between the HTMOS derived membranes and the DPhDMOS derived membranes was the deposition temperature range to obtain the higher $\mathrm{H}_{2}$ permeances. The temperature range for the HTMOS derived membranes was between $360^{\circ} \mathrm{C}$ and $450^{\circ} \mathrm{C}$, and that for the DPhDMOS derived membranes was between $150^{\circ} \mathrm{C}$ and $320^{\circ} \mathrm{C}$. The HTMOS derived membranes deposited at $450^{\circ} \mathrm{C}$ showed the high thermal stability that can be the best $\mathrm{H}_{2}$ permselective membrane. The excellent $\mathrm{H}_{2} / \mathrm{SF}_{6}$ permeance ratio of $5.6 \times 10^{6}$ was obtained because a pore size of the HTMOS derived membranes might be smaller than the pore size of the DPhDMOS derived membranes.

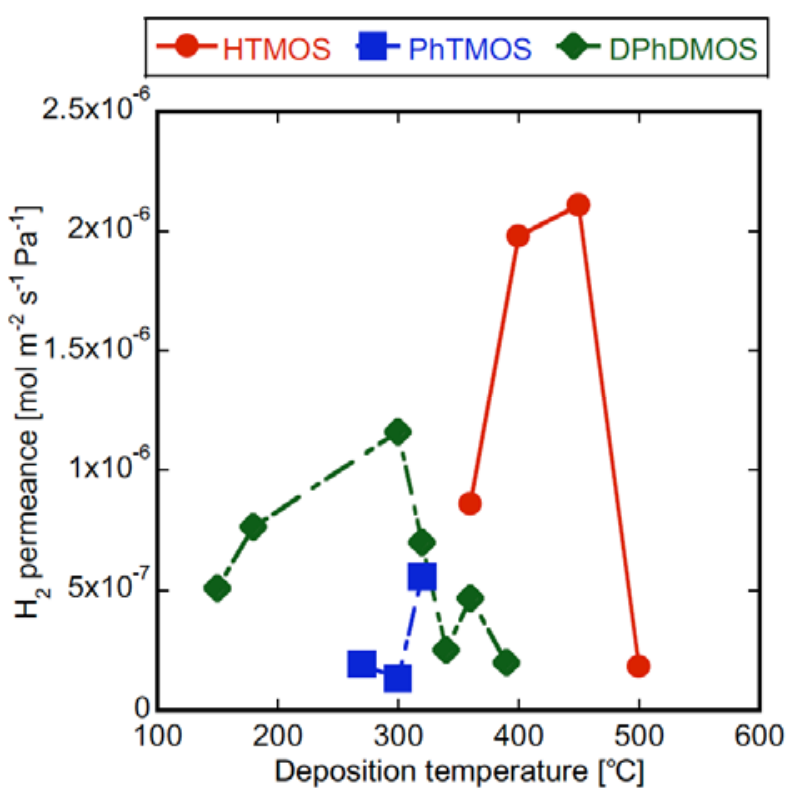

Figure 10: The trend of the $\mathrm{H}_{2}$ permeances for high $\mathrm{H}_{2}$ permselective membrane $\left(\mathrm{H}_{2} / \mathrm{SF}_{6}\right.$ permeance ratio $\left.>1000\right)$.

\section{CONCLUSIONS}

The maximum $\mathrm{H}_{2} / \mathrm{SF}_{6}$ permeance ratio of 560,000 was obtained with the $\mathrm{H}_{2}$ permeance of $2.1 \times 10^{-6} \mathrm{~mol} \mathrm{~m}^{-2}$ $\mathrm{s}^{-1} \mathrm{~Pa}^{-1}$ through the HTMOS derived membrane deposited at $450^{\circ} \mathrm{C}$. The $\mathrm{H}_{2}$ permeance was higher 
than those reported in the former reports. The DPhDMOS derived membrane deposited at $180^{\circ} \mathrm{C}$ showed a $\mathrm{H}_{2}$ permeance of $7.7 \times 10^{-7} \mathrm{~mol} \mathrm{~m}^{-2} \mathrm{~s}^{-1} \mathrm{~Pa}^{-1}$ with a $\mathrm{H}_{2} / \mathrm{SF}_{6}$ permeance ratio of 42,000 . These excellent membrane can be apply to the module for the dehydration of organic hydrides. The deposition mechanisms for these membranes were discussed by using the analysis for the hydrolysis powders of HTMOS and DPhDMOS.

\section{ACKNOWLEDGEMENT}

This work was partially supported by Council for Science, Technology and Innovation (CSTI), Crossministerial Strategic Innovation Promotion Program (SIP), "energy carrier" (Funding agency: JST) and has been partially supported by Grant-in-Aid for Scientific Research (C) (15K06548).

\section{REFERENCES}

[1] de Vos RM, Maier WF, Verweij H. Hydrophobic. J Memb Sci 1999; 277: 158.

[2] Nair BL, Okubo T, Nakao S. Structure. Membrane 2000; 73: 25-2.

[3] Kanezashi M, Asaeda M. Hydrogen. J Memb Sci 2006; 86: 271.
[4] Gavalas GR, Megiris C, Nam SW. Deposition. Chem Eng Sci 1989; 1829: 44-9.

[5] Okubo T, Inoue H. Single. AIChE J 1989; 845: 35.

[6] Tsapatsis M, Kim S, Nam SW. Ind Eng Chem Res 1991; 2152: 30.

[7] Ha HY, Nam SW, Hong SA, Lee WA. J Memb Sci 1993; 279: 85.

[8] Nakao S, Suzuki T, Sugawara T, Tsuru T, Kimura S. Preparation. Microporous Mesoporous Mater 2000; 145: 37.

[9] Nomura M, Ono K, Gopalakrishnan S, Sugawara T, Nakao S. J Memb Sci 2005; 151: 251.

[10] Nomura M, Aida H, Nakatani K, Gopalakrishnan S, Sugawara T, Nakao S, Seshimo M, Ishikawa T, Kawamura M. Ind Eng Chem Res 2006; 3950: 45.

[11] Gopalakrishnan S,Yoshino Y, Nomura M, Nair Balagopal N, Nakao S. A hybrid. J Memb Sci 2007; 5: 297.

[12] Khatib SJ, Oyama ST. Silica. Sep Purif Technol 2013; 20: 111.

[13] Gopalakrishnan S, Nomura M, Sugawara T, Nakao S. Preparation. Desalination 2006; 230: 193.

[14] Nomura M, Nagayo T. Monma Keita, Pore size. J Chem Eng Jpn 2007; 1235: 40.

[15] Matsuyama E, Ikeda A, Komatsuzaki M, Sasaki M, Nomura M. High-temperature. Sep Purif Tech 2014; 25: 128.

[16] Ikeda A, Matsuyama E, Komatsuzaki M, Sasaki M, Nomura M. Development. J Chem Eng Jpn 2014; 7:47.

[17] Ohta Y, Akamatsu K, Sugawara T, Nakao A, Miyoshi A Nakao S. Development. J Memb Sci 2008; 93: 315.

[18] Niimi T, Nagasawa H, Kanezashi M, Yoshioka T, Ito K, Tsuru T. Preparation. J Memb Sci 2014; 375: 455.

\section{DOI: http://dx.doi.org/10.6000/1929-6037.2015.04.02.4}

(c) 2015 lkeda et al.; Licensee Lifescience Global.

This is an open access article licensed under the terms of the Creative Commons Attribution Non-Commercial License (http://creativecommons.org/licenses/by-nc/3.0/) which permits unrestricted, non-commercial use, distribution and reproduction in any medium, provided the work is properly cited. 